
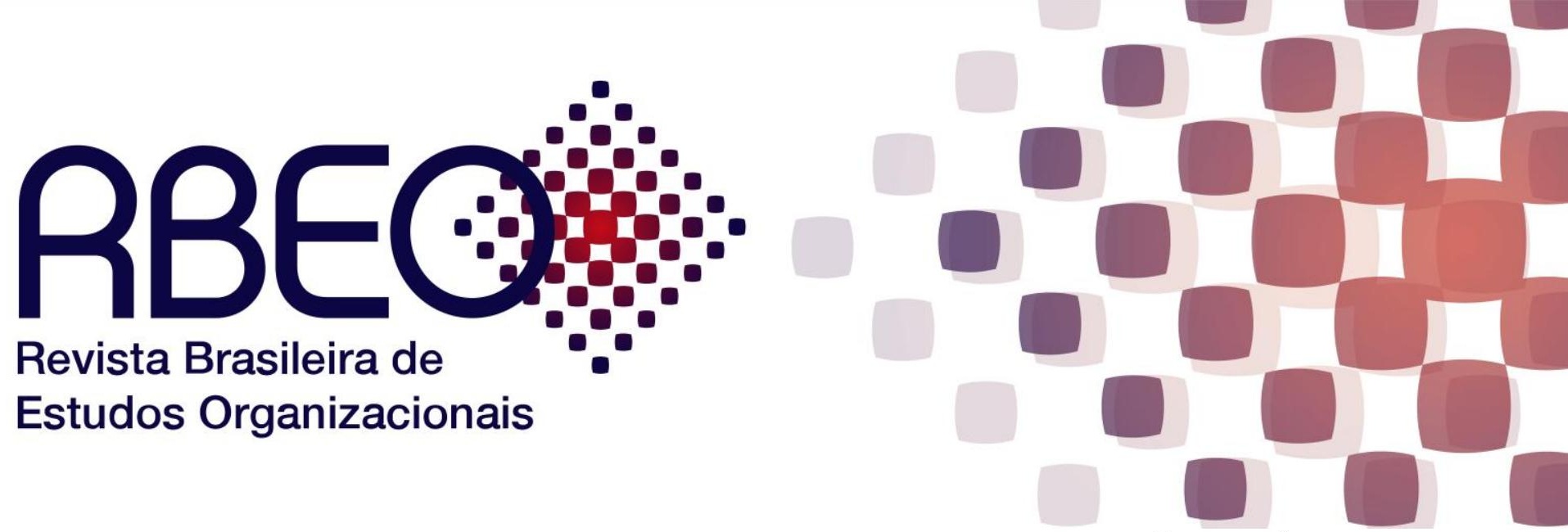

\title{
PARADIGMA HUMANISTA-RADICAL: UMA CONSTRUÇÃO TEÓRICA ALTERNATIVA PARA A ANÁLISE ORGANIZACIONAL
}

\author{
Giovanna Garrido ${ }^{1}$
}

Patrícia Saltorato $^{2}$

DOI: $10.21583 / 2447-4851 . r b e o .2018 . v 5 n 1.114$

\section{RESUMO}

Considerando a ortodoxia objetivista imperante no campo científico da Administração e a necessidade de uma visão mais liberta do objetivismo, este artigo apresenta-se como um desenvolvimento de cunho teórico. O objetivo é revisitar a obra de Burrell e Morgan (1979) visando explorar o paradigma sociológico-organizacional humanista-radical. Tal possibilidade paradigmática para a análise organizacional guarda em si conceitos de potencial sustentação aos debates que permeiam as organizações. Sendo assim, a referência ao Paradigma Humanista-Radical, bem como as suas pressuposições filosóficas simbolicamente representadas pela Metáfora das Prisões Psíquicas, se apresenta como uma tentativa de construção teórica alternativa capaz de desvendar e expandir os caminhos científicos em direções mais promissoras acerca de um melhor entendimento dos fenômenos organizacionais.

Palavras-chave: Paradigma humanista-radical. Metáfora da prisão psíquica. Análise organizacional.

\section{PARADIGMA HUMANISTA-RADICAL: UNA CONSTRUCCIÓN TEÓRICA ALTERNATIVA PARA EL ANÁLISIS ORGANIZACIONAL}

\section{RESUMEN}

Considerando la ortodoxia objetivista imperante en el campo de los estudios organizacionales y la necesidad de una visión científica más liberada de la razón, este artículo se presenta como un desarrollo de cuño teórico. El objetivo es revisar la obra de Burrell y Morgan (1979) para explorar el paradigma sociológico-organizacional humanistaradical. Tal posibilidad paradigmática para el análisis organizacional guarda en sí conceptos de potencial sustentación a los debates que permean a las organizaciones. Así, la referencia al Paradigma Humanista-Radical, así como sus presuposiciones filosóficas simbólicamente representadas por la Metáfora de las Prisiones Psíquicas, se presenta como un intento de

\footnotetext{
${ }^{1}$ Mestre em Engenharia da Produção. Pesquisadora no Centro de Tecnologia da Informação Renato Archer. Correio eletrônico: giovannagarrid@gmail.com.

2 Doutora em Engenharia da Produção. Professora do Programa de Pós-Graduação em Engenharia da Produção da Universidade Federal de São Carlos - Sorocaba (PPGEPS/UFSCar). Correio eletrônico: patriciasaltorato@gmail.com.
} 
construcción teórica alternativa capaz de desentrañar y expandir los caminos científicos en direcciones más prometedoras acerca de un mejor entendimiento de los fenómenos organizacionales.

Palabras clave: Paradigma humanista-radical. Metáfora de la prisión psíquica. Análisis organizacional.

\section{RADICAL-HUMANIST PARADIGM: AN ALTERNATIVE THEORETICAL APPROACH FOR ORGANIZATIONAL ANALYSIS}

\section{ABSTRACT}

Considering the objectivist orthodoxy in the field of organizational studies and the need for a more liberated scientific view of reason, this article presents itself as a theoretical development. The objective is to revisit the work of Burrell and Morgan (1979) in order to explore the sociological-organizational Humanist-Radical Paradigm. Such paradigmatic possibility for the organizational analysis holds in itself concepts of potential sustentation to the debates that permeate the organizations. Thus, the reference to the Humanist-Radical Paradigm, as well as its philosophical presuppositions symbolically represented by the Psychic Prisons Metaphor, presents itself as an alternative theoretical construction attempt capable of unraveling as well, expanding the scientific paths in more promising directions about a better understanding of organizational phenomena.

Keywords: Humanist-radical paradigm. Metaphor of psychic prison. Organizational analysis.

\section{INTRODUÇÃO}

São frequentes os debates a respeito da diversidade de pensamentos que permeia a realidade científica. Frente às diferentes visões e perspectivas que contempla, é notório que para todos os ramos da ciência existe uma infinidade de alternativas de teorização e pesquisa que acabam por gerar enormes debates na literatura (DAVIS, 1959; GIDDENS, 1976; HOMANS, 1964; GOULDNER, 1970; MEDEIROS; TEIXEIRA, 2014; MERTON; 1968; MILLS, 1959; PARSONS, 1937, PAULA, 2016).

Neste contexto, Burrell e Morgan (1979) desenvolveram um escopo analítico envolvendo muitos aspectos da filosofia e da teoria social como forma de ordenar e definir as diferentes visões científicas, a ponto de ser possível apreender o que há de comum ou de divergente entre elas (MORGAN, 1980). Estes autores se dispuseram a debater sobre a teoria social, em geral, e a teoria das organizações, em particular, em meio a um contexto sociológico mais amplo concebido em termos de quatro paradigmas que se portam como agrupamentos de visões da realidade social: Funcionalista, Interpretativo, Humanista-Radical e Estruturalista-Radical. 
Vale dizer que a determinação desses paradigmas promove cortes entre as visões científicas e endereça muitas teorias sociais àquilo que é fundamental para a determinação da forma como o pesquisador vê a realidade a qual se propõe a analisar. Deste modo, é a fundamentação dos mesmos em pressuposições diferenciadas de visões e interpretações dos fatos analisados que distingue as diferentes abordagens para a análise das organizações (BURRELL; MORGAN, 1979).

A questão é que, quando propuseram o desenvolvimento do modelo de categorização paradigmática, Burrell e Morgan (1979) modelaram perspectivas científicas voltadas à subjetividade - Paradigmas Humanista-Radical e Interpretativo - e à objetividade Paradigmas Funcionalista e Estruturalista-Radical -, atribuindo ênfase à possibilidade dessas diferentes perspectivas serem utilizadas para analisar uma vasta gama de teorias sociais e, inclusive, fatos e fenômenos organizacionais. Com isso, foi constituído um ferramental poderoso para a teoria das organizações (BURRELL; MORGAN, 1979), uma arena onde o dualismo de subjetividades e objetividades assume contornos agressivos.

Todavia, ao se analisar as bases do campo científico da Administração, as perspectivas objetivistas sempre alcançaram predominância no desenvolver das pesquisas (DAVIS, 1959; HOMANS, 1964; GIDDENS, 1976; GOULDNER, 1970; MERTON; 1968; MILLS, 1959; PECI, 2003; WILLMOTT, 1993), a ponto de constituírem a "ortodoxia" na realidade científica da área (DAVIS, 1959; GIDDENS, 1976; HOMANS, 1964; MERTON, 1968; MILLS, 1959; PARSONS, 1937; VERGARA; CALDAS, 2005). Por consequência, o debate acerca das organizações e dos fenômenos organizacionais expressa um extenso comprometimento com os ideais racionais dominantes; as explicações para fatos e fenômenos da realidade das empresas são advindas, principalmente, de um mesmo conjunto de pressuposições metateóricas,

Sendo assim, a incapacidade de promover um afastamento da visão de mundo tradicional, visto a sua contínua afirmação e reafirmação, faz com que tal visão assuma um status mais corriqueiro e mais inquestionável, restringindo a análise organizacional nos mais agudos termos e limitando-a em uma base científica cujas perspectivas metateóricas são fundamentadas de forma estreita e superficial (BURRELL; MORGAN, 1979).

Com a atenção voltada àquilo que possa ser diretamente observável, as análises dos fenômenos organizacionais são submergidas em meio a uma objetividade excessiva que 
desconsidera qualquer teor que, de certa forma, submeta-as a uma visão mais subjetiva dos fatos. Isto é, a uma visão que permite ir além daquilo que é tangível e passível de observação, atribuindo às análises a capacidade de desvendar as emoções, os sentimentos e as interioridades dos indivíduos que compõem os fenômenos observados.

Deste modo, considerando a hegemonia exercida pela abordagem objetivista nas análises organizacionais (PARSONS, 1937; MILLS, 1959; DAVIS, 1959; HOMANS, 1964; MERTON; 1968; GIDDENS, 1976; CALDAS; FACHIN, 2005), o presente estudo justifica-se pela necessidade de uma visão científica mais liberta do objetivismo. Para tanto, por considerar o paradigma Humanista-Radical como uma possibilidade paradigmática de análise organizacional que guarda em si conceitos de potencial sustentação ao debate dos fenômenos organizacionais, este estudo apresenta-se como um desenvolvimento de cunho teórico cujo objetivo é revisitar a obra de Burrell e Morgan (1979) visando explorar o paradigma sociológico-organizacional humanista-radical.

Para tanto, o estudo primeiramente contextualiza as bases do campo científico da administração, deixando explícito o argumento teórico da pesquisa em termos da fragilidade e da parcialidade das análises dominantes, e a forma como o desconhecimento da diversidade paradigmática tem aprisionado e limitado o desenvolvimento científico da área. Subjacente a esta contextualização, o estudo faz referência ao paradigma sociológicoorganizacional humanista-radical, apresentando-o como uma possibilidade paradigmática que, sendo simbolicamente representada pela Metáfora das Prisões Psíquicas, se constitui como potencial sustentáculo ao debate dos fenômenos organizacionais.

\section{A PARCIALIDADE DAS ANÁLISES ORGANIZACIONAIS PREDOMINANTES}

Embora já exista uma longa tradição delineada pela psicologia organizacional, é notório que as perspectivas teóricas de cunho subjetivista ainda são perspectivas de pouca presença nas análises do mundo organizativo (DAVIS, 1959; GIDDENS, 1976). A busca nos principais índices sobre Comportamento Organizacional e Teoria das Organizações revela poucas chamadas, quando existem, sobre aspectos de análise que incluem as emoções, os sentimentos e as interioridades dos indivíduos.

Isso transparece o atual status do campo científico da Administração (FINEMAN, 2009) e revela a predominância alcançada pelos ideais objetivistas no desenvolver das 
pesquisas (DAVIS, 1959; HOMANS, 1964; GIDDENS, 1976; GOULDNER, 1970; MERTON; 1968; MILLS, 1959; PECI, 2003; WILLMOTT, 1993) bem como a forma como constituem a "ortodoxia" na realidade científica da área (DAVIS, 1959; GIDDENS, 1976; HOMANS, 1964; MERTON, 1968; MILLS, 1959; PARSONS, 1937; VERGARA; CALDAS, 2005).

Neste cunho analítico, pelo fato de o mundo social assumir uma natureza ontológica realista e aparecer como algo concreto e imutável, como uma realidade objetiva externa à cognição individual, sempre coube à ciência buscar leis universais capazes de explicar e governar esta realidade observada, e também identificar e definir todos os seus elementos e a forma com que o relacionamento entre eles é expresso (BURRELL; MORGAN, 1979).

Durante o processo de consolidação da teoria das organizações e estendendo-se por muito tempo, os postulados metodológicos do quadro teórico positivista e a teoria geral dos modelos funcionalistas exerciam predominância (DAVIS, 1959; MERTON; 1968; GIDDENS, 1976; MOZZATO; GRZYSGOVSKY, 2011; PRATES; RODRIGUES, 2009). Como um conceito descritivo usado na caracterização das epistemologias de pesquisa, o debate positivista defende essa possibilidade de explicar e prever os acontecimentos do mundo social por meio da análise das regularidades e dos relacionamentos causais entre os elementos que o constituem. Ou seja, é uma essência de pesquisa que tem como base as abordagens tradicionais dominantes e o conhecimento acumulado resultante destas (BURRELL; MORGAN, 1979).

Lima (2011) afirma que a visão positivista assume a existência de um mundo, ou uma realidade social objetiva, que pode ser representado, com maior ou menor presteza, por meio da utilização de métodos científicos capazes de mensurar e descrever suas propriedades de forma independente daquele que o observa e dos instrumentos que utiliza. Isto é, os pressupostos positivistas visam, costumeiramente, fazer das pesquisas um teste de teorias já estabelecidas cujos dados são coligidos e processados objetivamente de forma a aumentar a compreensão preditiva dos fenômenos que analisam.

Assim, de acordo com Morgan (1980), diante desta grande influência dos pressupostos positivistas, os teóricos do campo científico da administração abordam seus objetos de estudo por meio de referenciais cujas bases se fundam em pressuposições estabelecidas além da percepção consciente. A incapacidade de promover um afastamento da visão de mundo tradicional, visto a sua contínua afirmação e reafirmação pelos cientistas 
da área, faz com que essas pressuposições assumam um status mais corriqueiro e mais inquestionável. Desta forma, restringe-se a análise organizacional nos mais agudos termos, limitando-a em uma base científica cujas perspectivas metateóricas são fundamentadas de forma estreita e superficial (BURRELL; MORGAN, 1979).

Em meio a este caráter predominante da ciência prevalecem as correntes teóricas que enxergam as organizações com essa mesma objetividade conferida ao mundo social, como estruturas concretas e objetivas cujas ações se resumem meramente como respostas às diversas condições objetivas do ambiente. Ou seja, analisadas através deste cunho analítico limitador, prevalecem as ênfases naquilo que é geral e universal das organizações, ao invés de enfatizar o que é único e particular dos indivíduos que as compõem. Isso mostra o quanto os processos sociais e culturais que dão forma à estrutura e ao comportamento são coisificados como meras variáveis exógenas de análise (BURRELL; MORGAN, 1979; PECI, 2003).

Deste modo, pode-se caracterizar a realidade científica da área organizacional como uma vasta proporção de teorias e pesquisas limitadas, principalmente, aos ideais de apenas um dos paradigmas sociológicos de Burrell e Morgan (1979): o Paradigma Funcionalista. É visível a predominância assumida pela ortodoxia funcionalista e a visão materialista e objetivista dos fatos organizacionais (DAVIS, 1959; GIDDENS, 1976; MERTON; 1968; SANTOS, 2017).

Vale ressaltar o argumento de Reed (2010) de que o núcleo teórico e ideológico das análises organizacionais impregnou-se do modelo racionalista de forma tão abrangente e natural que tal influência se tornou impossível de ser detectada ou mesmo questionada. Embutido profundamente nos fundamentos epistemológicos e teóricos das perspectivas analíticas que constituem o cerne das investigações dos fenômenos organizacionais, o objetivismo exerceu, e ainda exerce, grande presença no desenvolvimento histórico e conceitual das análises do mundo organizativo, estabelecendo um modelo e uma pauta de pesquisa difíceis de serem ignorados.

Com a atenção voltada àquilo que é diretamente observável, as análises das organizações são submergidas em meio a uma objetividade excessiva que exerce domínio sobre qualquer teor que, de certa forma, submeta-as a uma visão mais subjetiva dos fatos. Preceitos normativos, passíveis de questionamentos, se transformam em leis universais, 
objetivas, imutáveis e, consequentemente, inquestionáveis (DAVIS, 1959; MERTON; 1968; REED, 2010), que acabam por reger todo o desenvolvimento científico.

Devido à sua representatividade institucional, essa forma ortodoxa de pensamento tem conduzido toda a sociologia acadêmica e continua expandindo sua hegemonia no campo científico da administração (DAVIS, 1959; GIDDENS, 1976; HOMANS, 1964; MERTON, 1968; MILLS, 1959; VERGARA; CALDAS, 2005). Pelo fato de ser tão dominante e concreta, os teóricos acabam por considerá-la taken for granted, correta e autoevidente (BURRELL; MORGAN, 1979).

É possível contemplar certa tendência das pesquisas em reificar o elemento "Organização" (PECl, 2003), reduzindo-o em valores meramente materialistas. Fundamentada em pressupostos raramente explicitados, é possível inquirir que a Teoria das Organizações se desenvolve em bases não questionadas (MORGAN, 1980).

Aqui, cabe um argumento de Feyerabend (1977) quanto ao poder de condução do pensamento científico imperante na sociedade. Diante do exposto, é possível inquirir que se tornou um dado o fato de posicionar o pensamento em concórdia aos discursos sociais vigentes e não se opor a eles. Antes, o submete à aparente "verdade" e a dissemina, o que faz dela algo ainda mais inquestionável, a ponto de parecer obrigatório. Tal argumento transparece o combate frente a tudo àquilo que não é coberto pelo discurso imperante, ou seja, parece não haver espaço para nada que não seja sustentado pelo tal.

A gravidade desta concórdia é explícita no argumento de Burrell (2010). O autor argumenta que, ao voltar os olhos para trás, torna-se possível visualizar que o campo científico da Administração consolidou-se como um campo onde teóricos poderosos concordaram em dar pouca atenção aos problemas fundamentais ao direcionarem questões fundamentais. Deste modo, a falta de questionamento e a contínua reprodução da herança científica transparecem quão fraturada se encontra a realidade das análises organizacionais.

Assim, não é de se surpreender ao afirmar que, na tentativa de proclamarem o entendimento do mundo organizacional, os teóricos reduzem a dinâmica do mesmo, aprisionando-o em um sistema classificatório estático, em uma estrutura compreensível e simplificada. As conceituações da Teoria das Organizações apenas se desenvolvem como formas de reforço da estagnação da dinâmica da vida real, aprisionando a estrutura de 
pensamento com considerável sofisticação, como uma espécie de encarceramento, vitimando-a a ponto de se tornar um mero objeto de legenda (BURRELL, 2010).

O conceito escreve suas marcas sobre o corpo da literatura e, no processo de marcar com cortes e incisões, deixa um rastro de lesões atrás do qual todos podem seguir. Os cortes mais profundos são aqueles que deixam as maiores impressões [...] Contudo, esses magníficos cortes, em última análise, significam morte e imobilidade. No mínimo, o assunto é ferido pelos mais profundos e incisivos rótulos (BURRELL, 2010, p.441).

Pelo fato de não possuir o tamanho correto, a ponto de encaixar-se nesta estrutura paralisada na qual vem sendo imobilizada, Burrell (2010) argumenta que a análise organizacional permeia em um Leito de Procusto. O reforço exacerbado de conceitos já definidos previamente desconsidera a questão de que todo o conceito inclui e também exclui; ignora e também se concentra; obscurece e também traz aos refletores. Isto é, desconsidera-se a questão de que não há limites para os conceitos.

Diante disto, Burrell e Morgan (1979) chegam a questionar a legitimidade de muitas teorias e pesquisas organizacionais contemporâneas. Os autores demonstram certa preocupação com o fato de se atribuir às organizações uma natureza essencialmente efêmera, visto a quantidade de teorias geradas pelas análises organizacionais que não possuem relação aparente fora de seus contextos. Inclusive, tal preocupação se alastra para todas as ciências sociais contemporâneas, já que prevalece o domínio de métodos de pesquisa abstraídos da diversidade de assuntos extensos que, ostensivamente, são designados a examinar e cujos resultados se limitam ao abstrato, com fins em si mesmos (MORGAN; SMIRCICH, 1980).

Tudo isso mostra quão limitadora e danosa é a orientação predominante das análises organizacionais. Elencando formas de interpretações como sendo mais populares, politicamente superiores e comuns, pouca ou mesmo nenhuma menção é oferecida ao caráter científico pluralístico, o qual considera não apenas uma única entrada possível aberta para a análise das organizações (BURRELL, 2010).

Percebe-se que as forças funcionalistas persistem na determinação de pressuposições teóricas relacionadas à regulação e à objetividade, ou seja, tornaram-se lesões entalhadas no corpo das análises organizacionais (BURRELL, 2010). Com a incrível capacidade de tradução daquilo que é de fora para seus próprios termos, as forças 
funcionalistas permanecem muito bem entrincheiradas (VERGARA, 2010). Calcadas no determinismo e apresentadas como objetivistas e pragmáticas, buscam sempre se orientar pelos métodos das ciências naturais nas tentativas de ordenar a realidade as quais analisam, inquirindo que tudo obedecerá a ordem social regulada do ambiente e dando não muita atenção ao papel exercido pela subjetividade humana, como se isso fosse possível (GUIDENS, 1976; MOZZATO; GRZYBOVSKI, 2011).

Parafraseando Burrell (2010), pode-se afirmar que essas forças objetivistas acabam aprisionando, imobilizando e ferindo aquilo a que buscam se referir. Ou seja, apeando no quadro explanatório objetivista, como uma temível arma de mutilação, as análises organizacionais oferecem o fenômeno a ser explicado à execução, restringindo-o a vieses analíticos ordenados, determinados, racionalizados e regulados. Com isso, os gemidos dos atores que estão por trás do fenômeno são abafados e desconsiderados.

Como bem observado por Clegg e Hardy (2009), o espectro imperante de análise organizacional tem o potencial de negligenciar o sujeito. No realizar das pesquisas à custa do mesmo, os acadêmicos obedecem à tendência de articular seus pensamentos, receios e visões de mundo de forma racional e lógica, perdendo de vista as pessoas que constituem as organizações. Na investigação das forças sociais e ambientais que atuam como determinantes das ações organizacionais, as abordagens de análises enfatizam, primordialmente, o papel das dimensões objetivistas e quase naturais (PRATES; RODRIGUES, 2009).

Os teóricos não se permitem lograr um distanciamento da visão tradicional de mundo e de seus conhecimentos prévios racionalizados acerca daquilo que analisa (MORGAN, 1980), já que olhar mais atentamente aos elementos subjetivos requer novas pressuposições, nova teoria, e árdua é a separação da objetividade e o psiquismo humano (GUIDENS, 1976; MOZZATO; GRZYBOVSKI, 2011).

Embora tenha havido um início tímido de mudança, diante dos questionamentos de âmbito cultural e das evidenciações das dimensões mais qualitativas do mundo organizativo (PECl, 2003), as críticas e teorias que se propuseram a ressuscitar o sujeito nas análises organizacionais não foram suficientes para romper o paradigma racional instrumental dominante (MOZZATO; GRZYBOVSKI, 2011). Quando tais temas ganham destaque, as discussões são feitas por terminologias genéricas e teóricas que as tornam incapazes de 
beneficiar o sujeito. Ao mesmo tempo em que clamam, marginalizam o mesmo. Ao mesmo tempo em que lutam por fazê-lo transparecer, desbotam-no. Portanto, encapsuladas e homogeneizadas por estas suposições tenras, as vozes dos sujeitos e sua individualidade permanecem no som do silêncio e são pronunciados como mortos (CLEGG; HARDY, 2009).

Clegg e Hardy (2009) argumentam que tal realidade faz com que essas teorias não se diferenciem totalmente do positivismo contra o qual resistem. Assim como o mesmo, elas marginalizam e silenciam o sujeito de quem falam, reduzindo-o a estatísticas ou incluindo-o em contextos nos quais o mesmo não é capaz de falar por si mesmo. Isto é, um contexto que garante ao sujeito um status de pouco mais que um boneco de ventrículo.

Verdade seja dita: ao se apegar a esse foco objetivo de análise, que ao mesmo tempo em que ressuscita emudece o sujeito, ignora-se o fato de que a organização, composta por indivíduos, é um sistema cujos preceitos são de muita complexidade. A adoção de uma postura que afasta estes indivíduos para as margens das análises organizacionais é o mesmo que defender o incompleto.

Clegg e Hardy (2009) afirmam que os sinais da identidade dos indivíduos requerem contemplação. Considerá-los como seres lógicos e racionais posicionados como meros recipientes de determinantes ambientais (SILVA; VERGARA, 2003) é o mesmo que tapar os olhos perante a verdadeira análise organizacional, é negar a essência da representação humana em cada ação organizacional. Isto é, analisar os fenômenos organizacionais apoiando-se, principalmente, em conceituações objetivas é não se importar com a amplitude e completude das análises, é se contentar com apenas um quadrante científico, físico, tático e incompleto. Mozzato e Grzybovski (2011) afirmam que o mundo está a cada dia mais fragmentado e incerto e não está em consonância com o desejo de ordem que propõe a ortodoxia funcionalista.

Ressalta-se aqui que a maneira como a vida organizacional é constituída tem muitas dimensões inconscientes. Lamentações, ansiedade, frustrações, tédio e desespero são partes de toda a criação social e expressões individuais da vida organizacional. Nesse sentido, muitos fenômenos organizativos possuem explicações advindas do âmbito não racional. Interpretar dados, tomar decisões, persuadir, lutar, resistir e sobreviver, é mais do que um conjunto de respostas automáticas passíveis de análise objetiva, são fenômenos sentidos e formados por sentimentos (FINEMAN, 2009). 
Em suma, pode-se dizer que existem muitos caminhos para a reconexão com os habitantes das organizações. Ao mesmo tempo em que a maioria das pesquisas convive com o risco de perder o sujeito de vista, elas também são potenciais para relocalizarem o mesmo. Ao acreditar que nada pode ser feito e que não é possível iniciar a diferença é o mesmo que se acorrentar às ideias e deixar com que os controladores determinem o modo comum de analisar o mundo organizativo. Ou seja, é permitir a própria condução à tirania intelectual (CLEGG; HARDY, 2009).

Cabe agora a adoção de um comportamento resistente a essa tirania, propiciando medidas capazes de reverter este caos científico, revendo as bases em que as prioridades de pesquisa devem se assentar (PRATES; RODRIGUES, 2009). Devido à representatividade que o indivíduo exerce no âmbito organizacional, deve-se sempre priorizar os elementos subjetivos da análise organizacional, atribuir valor àquilo que não é observado diretamente. Teorizar sobre as organizações não é se apegar somente naquilo que é concreto e racional, como fazem as perspectivas predominantes, mas é abraçar outros quadros de referência e se adentrar também por critérios de análise na tentativa de compreender, se não tudo, mas uma parte daquilo que está por trás dos atores e das ações organizacionais.

Por este motivo, vale considerar que a ênfase em critérios alternativos de pesquisa não consiste no impedimento da utilização de rotas tradicionais, mas, antes, pressupõe superá-las por meio de uma postura científica diferenciada, mais reflexiva, mais crítica e com menor teor de rigidez e intransigência (MELO, 2008; VERGARA, 2010). Acredita-se que é possível desenvolver um conhecimento que, ao invés de excluir e fragmentar, integre e englobe, evitando uma visão desatualizada, doutrinária e acrítica (SANTOS, 2017).

Afinal, os modos de pesquisas tradicionais, ligados à racionalidade e à objetividade, foram notadamente bem sucedidos, porém vislumbrou-se, mais do que nunca, a necessidade de enfatizar outras narrativas e epistemologias científicas (BURRELL, 2010). Torna-se necessário firmar mais as bases subjetivistas das análises organizacionais estabelecendo-as não como meras realidades de pesquisas alternativas comprimidas pelo objetivismo analítico predominante, mas como detentoras de conceitos, ideias e visões que devem ser mais debatidas para a real compreensão do comportamento organizativo.

Ressalta-se, ainda, a necessidade de maior ênfase nas realidades alternativas às dominantes, isto é, um desenvolvimento em termos paradigmáticos que atribui ao indivíduo 
um papel efetivo de ator social e não como mero sujeito da ciência e do mundo (GUIDENS, 1976; MOZZATO; GRZYBOVSKI, 2011). Cabe uma maior atenção ao realizar científico subscrito alternativamente à visão dominante que permeia as pesquisas organizacionais, enfatizando mais a experiência subjetiva e a psique humana e as considerando como requisitos fundamentais para o entendimento da forma como os indivíduos criam, modificam e interpretam o mundo e a realidade na qual se inserem.

Em suma, parafraseando Burrell e Morgan (1979), urge como necessário um olhar mais profundo nas análises organizacionais, até mesmo porque a dimensão subjetiva existe mesmo nos aspectos mais tangíveis da vida organizacional (BASTOS; BORGES-ANDRADE, 2009). Cabe aos teóricos um maior empenho na adoção de metodologias alternativas de pesquisa, fundamentando-se na ideia de que só é possível compreender um mundo social enfatizando também as abordagens subjetivas de análise, das quais é possível filtrar um conhecimento de primeira mão e não um conhecimento subordinado a um rigor científico formulador de hipóteses (BURRELL; MORGAN, 1979).

Levando em conta a importância de se livrar da ortodoxia objetivista e de se adentrar aos méritos mais subjetivos de análise organizacional, as pressuposições presentes no Paradigma Humanista-Radical, simbolicamente representadas pela Metáfora das Prisões Psíquicas (MORGAN, 2007), apresentam-se como uma das possibilidades paradigmáticas subjetivistas existentes que são capazes de articular o conhecimento da realidade organizacional de forma mais condizente ao contexto complexo que se encontra.

\section{O ARCABOUÇO INTELECTUAL HUMANISTA}

O Paradigma Humanista-Radical se constitui como uma vertente sociológica que tem sua origem intelectual traçada nos contornos da tradição de pensamento social Idealista Alemão e na noção Kantiana de que a realidade do universo assume uma natureza mais espiritual do que material (BURRELL; MORGAN, 1979).

A tradição intelectual do Idealismo Alemão exerceu um amplo domínio sobre as ciências sociais nos últimos cem anos, apesar do pouco entendimento e simpatia por parte dos teóricos organizacionais anglófilos (BURRELL, 2010). Seu cerne referenciado como 
transcendental, subjetivo e absoluto reflete uma filosofia social que tem como ênfase a natureza essencialmente espiritual do mundo social (BURRELL; MORGAN, 1979).

Vale enfatizar aqui, que essa noção de espiritualidade trazida pelos ideais humanistas merece referência no que se refere ao seu significado. Leitão e Lameira (2005) enfatizam que a espiritualidade humanista é uma dimensão da experiência do indivíduo que abrange seus sentimentos, suas intuições, suas perspectivas, entre outras capacidades da consciência transcendental de todos os seres humanos.

Submergido na dimensão subjetivista de abordagem das Ciências Sociais, o enfoque humanista-radical, quanto às suas características ontológicas, epistemológicas, da natureza humana e da metodologia que emprega, predomina-se, respectivamente, no nominalismo, no antipositivismo, no voluntarismo e na metodologia ideográfica (BURRELL; MORGAN, 1979).

Tendo como base seu viés subjetivista e as filosofias que a sustentam, pode-se considerar que tal entidade paradigmática considera o ser como alguém que tem o potencial de transcender todo o conhecimento que tem em relação a um fenômeno, sendo ele a própria base deste conhecimento (SARTRE, 1966).

Guardadas as suas convergências sociológicas com o outro quadrante subjetivista no que se refere à noção do indivíduo como criador do mundo em que vive (DRAGO, 1992; SANTOS, 2017), a essência da orientação subjetiva humanista é fundamentalmente disposta a servir fins diferenciados (BURRELL; MORGAN, 1979). Em contraposição ao ideal interpretativista, que se fundamenta em uma abordagem de ordem e regulação social, o paradigma humanista-radical questiona e combate tal perspectiva, enfatizando a sua falta de engajamento em prol da mudança social (VERGARA; CALDAS, 2005).

Assim, essa vertente não tenta somente compreender o mundo, mas também modificá-lo (GUIDENS, 1976; MOZZATO; GRZYBOVSKI, 2011). Para tal, possui como esquema de referência uma visão de sociedade que enfatiza a necessidade de se transcender as limitações dos arranjos sociais. Ou seja, é uma vertente sociológica que se define pelo seu próprio interesse em voltar-se à sociologia da mudança radical, do ponto de vista subjetivo (GUIDENS, 1976).

Além disso, por mais que a base argumentativa de ambos os paradigmas subjetivistas de Burrell e Morgan (1979) vise a realidade como algo socialmente criado e sustentado, o 
paradigma humanista-radical se diverge naquilo que propõe. O ideal interpretativista visa entender a natureza desse processo de criação, enquanto o humanista, por sua vez, visa criticar e levar em menção o estado de aprisionamento psíquico que o indivíduo adquire em suas próprias criações (BURRELL; MORGAN, 1979; MORGAN, 1980; SANTOS, 2017).

A crítica humanista-radical frente a este aprisionamento psíquico na esfera social procede ao longo de duas linhas de discurso, o "subjetivismo idealista" e o "objetivismo idealista" (BURRELL; MORGAN, 1979). Vale dizer que cada uma delas é empenhada em um quesito capaz de cumprir o interesse que permeia tal vertente em descobrir como a ação resultante dos modos de pensar dos indivíduos pode ser vista como uma forma de transcender este aprisionamento alienado que os consome (MORGAN, 1980).

Constante em sua raiz subjetivista, na primeira linha de discurso, fundamentada, sobretudo, nas filosofias de Husserl e Fichte (1889), a perspectiva humanista dispõe de uma ênfase especial nos aspectos da consciência humana. Vista como a força criadora e sustentadora do mundo social, a consciência humana passa a ser notada como uma entidade criativa que guarda em si ideias, conceitos e perspectivas por meio dos quais é criado o mundo que lhe é externo (BURRELL; MORGAN, 1979).

Os argumentos de Fichte (1889) são ricos ao promover uma reflexão no que se refere ao relacionamento entre esse enaltecimento da menção do papel da consciência humana, e os ideais epistemológicos de tal entidade paradigmática. Na visão do autor, a característica da ciência consiste na relação entre o seu conteúdo e a consciência do indivíduo de quem o conhecimento é declarado. Como se nota, Fichte (1889) reforça que o conhecimento não consiste em algo que existe independente do indivíduo, mas que é produzido pela própria liberdade da mente humana quando trabalhada em uma direção específica.

Considera-se que as colocações de Fichte (1889) enfatizam as nuances antipositivistas do paradigma em questão. Há uma ressalva na menção de que o conhecimento se refere e tem como base a consciência individual, e que toda a primazia do mesmo é abandonada no momento em que se busca estabelecê-lo como algo rígido e real (SARTRE, 1966).

Consequentemente, pelas próprias implicações destas considerações acerca da consciência, da ciência e do conhecimento, os contornos ideográficos humanistas também são reforçados nessas colocações. Diferente do que defendem os ideais da metodologia 
nomotética, Fichte (1889) afirma que o realizar científico sistemático parece ser apenas uma qualidade acidental para a ciência e não a sua verdadeira essência.

Sendo assim, pela própria visão enfática dada aos méritos da consciência, a linha de discurso subjetivista idealista, tendo como base as filosofias que a fundamentam, enfatiza que, na busca pelo entendimento do mundo social ou mesmo de uma realidade criada, torna-se necessário o prévio entendimento da natureza, da estrutura e do funcionamento da mente humana (BURRELL; MORGAN, 1979).

Porém, vale afirmar que, para o entendimento da mente, deve-se sempre considerar o argumento de Sartre (1966), o qual enfatiza que embora apareça como uma entidade de um enorme vazio, pelo fato de o mundo todo se encontrar externo a ela, a consciência humana é em si o absoluto. É por isso que Harris (1889), enaltecendo as filosofias de Kant, alega que o conhecimento da estrutura da mente não consiste em um mero entendimento das "formas da mente", mas também um conhecimento das próprias condições de existência.

Fichte (1889) argumenta que, para a explanação dos fatos da consciência empírica, a questão do Ego humano deve ser a base de todo argumento. Isto é, antes mesmo de qualquer outro tipo de colocação, deve-se considerá-lo, visto que, sendo um campo transcendental (SARTRE, 1966), é nele que repousa a base de toda a consciência humana e é unicamente ele que a faz possível (FICHTE, 1889). Aliás, são por estas considerações que Fichte (1889) denota a questão do Ego como o princípio fundamental do conhecimento humano; um princípio único, absoluto e incondicional, enaltecendo mais uma vez a epistemologia Antipositivista das visões humanistas-radicais.

Com um raciocínio similar, Sartre (1966) afirma que os dados, menções e fatos da consciência humana provêm do limbo do inconsciente. Embora haja ciência da incapacidade de entender absolutamente de onde deriva a existência do mesmo, o inconsciente tem o potencial de perpetuar sua existência e, ainda, de produzir a própria consciência. Deste modo, observa-se que o entendimento da mente humana requer algo além do que um mero decifrar de suas manifestações.

Em concórdia com o argumento de Drago (1992) de que mundo social e a consciência individual se portam como dois lados de uma mesma realidade, os subjetivistas idealistas afirmam que o mundo e a realidade podem ser entendidos em termos da projeção da 
consciência individual (BURRELL; MORGAN, 1979). Desta forma, vista a relação entre ambos, para que se entenda o mundo social é necessário se ter ciência da relação estreita entre a manifestação da mente humana e tudo o que ocorre na psique dos indivíduos.

Galgando maiores níveis de abstração neste ponto, ao se ter ciência de que a forma de agir da mente humana é dada e sustentada pela questão do Ego e por questões que escapam da racionalidade, obtêm-se, então, uma categoria de realidade para o indivíduo. Ou seja, qualquer ideal que seja colocado e faça parte do Ego humano passa a ser sua realidade, sua essência (FICHTE, 1889).

De modo que, sendo movidos segundo a própria mente, muitos atos e comportamentos humanos na realidade social podem ser considerados como reflexos externos das lutas que ocorrem no interior dos indivíduos. Até mesmo porque o que define o ser humano são seus próprios desejos, considerados como entidades psíquicas que fazem morada na consciência do mesmo (SARTRE, 1966). É por este motivo que Drago (1992) enfatiza que o ser humano vive em um mundo caracterizado pelo relacionamento constante entre a consciência individual e a sua objetivação na realidade externa.

Sendo explícitas tais considerações, pode-se afirmar que o indivíduo externaliza na realidade que cria tudo aquilo que lhe é oculto, visto que, quando assim o faz, o mesmo toma consciência sobre si próprio e sobre as ações que pratica (BURRELL; MORGAN, 1979). Partindo disso, é possível dizer que a realidade criada passa a ser uma fonte de identificação na qual o indivíduo se prende e, mesmo que inconscientemente, a reproduz.

É neste ponto que os subjetivistas idealistas radicalizam a perspectiva de discurso que os sustenta, vendo o indivíduo como um ser imobilizado psiquicamente dentro dos próprios modos de existência que cria (BURRELL; MORGAN, 1979). Morgan (1980) e Santos (2017) descrevem que ele se aprisiona dentro das fronteiras da realidade que ele próprio cria e sustenta. O seu próprio agir o faz dominado ideologicamente por superestruturas que interferem na forma como ele mesmo se relaciona com sua verdadeira consciência, impedindo o seu pleno desenvolvimento (BURRELL; MORGAN, 1979; DRAGO, 1992; LAING, 1967).

De forma geral, pode-se inquirir que, em função deste discurso subjetivista, os ideais do paradigma humanista-radical se baseiam na visão de que o processo de criação da realidade pode ser influenciado por forças psíquicas e sociais capazes de canalizar, restringir 
e controlar a mente do indivíduo de maneira a aliená-lo em relação às potencialidades inerentes à sua própria e verdadeira natureza de ser humano (MORGAN, 1980).

Assumindo, de princípio, um viés minimamente distinto e fundamentado, principalmente, nas filosofias de Hegel, a linha de discurso "objetivismo idealista" do paradigma humanista-radical também considera a consciência humana como um quesito fundamental para o entendimento da natureza do mundo social. Todavia, enquanto no discurso "subjetivista idealista" o indivíduo, segundo sua consciência, é capaz de criar seu próprio mundo, essa linha de discurso enfatiza que a consciência individual está sujeita a uma razão universal. Tal visão concretiza a existência de uma força ou espírito absoluto que circunda o indivíduo e o integra (BURRELL; MORGAN, 1979; DRAGO, 1992).

Ressalta-se que Hegel e esses principiantes contornos do "objetivismo idealista" foram sujeitos a uma vasta gama de interpretações. De notória posição entre os "Hegelianos" de esquerda, Karl Marx se pôs em distorção ao sistema de pensamento de Hegel, o direcionando a fins fundamentalmente diferenciados e trazendo novamente a figura do indivíduo e de sua consciência sobre a noção do espírito absoluto enfatizada por ele. Foi estabelecido, mais uma vez, que todas as objetificações vistas no mundo social são criações do homem e não há nada de absoluto acima de si (BURRELL; MORGAN, 1979; DRAGO, 1992).

Mais uma vez, houve um realce na premissa do aprisionamento psíquico, enfatizando a forma como criações sociais objetificadas são capazes de dominar toda a essência e natureza do indivíduo. Pode-se considerar, acima de tudo que, até mesmo pela capacidade de construção e sustentação da realidade que lhe foi concedida e ao papel dispensado à sua consciência no desenvolver desta, a construção da realidade externa não deixa de ser uma corporalização da psique do indivíduo. No entanto, tal corporalização gera um estado de ossificação ao mesmo, afetando seus instintos, suas inibições, suas modificações, enfim, sua dinâmica original de ser humano torna-se meramente estática (BURRELL; MORGAN, 1979; MARCUSSE, 1975).

Segundo Burrell e Morgan (1979), essa realidade criada pode se tornar tão intensa e tão real para o indivíduo, a ponto de restringir as ações e as orientações do mesmo. Isto é, sua própria alienação promove o ajustamento e a adaptação de sua consciência de forma que o indivíduo enxergue todos os aspectos de suas criações como verdadeiros, reais, enfim, 
como algo que Ihe traz beleza aos olhos (LAING, 1967). É como se a realidade criada assumisse para si e deixasse transparecer não mais uma natureza nominalista da Ciência, mas realista, como se existisse por seu próprio critério.

Consequentemente, da mesma forma que a construção da realidade social não deixa de ser uma corporalização da psique, é notável que a corporalização da psique na realidade criada não deixa de ser um processo de aprisionamento psíquico. O inconsciente do indivíduo torna-se inteiramente apropriado por suas criações e escravizado por si mesmo, a ponto de reproduzir visões artificiais de mundo - frutos dos aspectos alienantes que o consomem. Se a máscara desta alienação cair, o indivíduo pode se deparar com um imenso vazio (FREDDO, 1994).

Nota-se, portanto, que o estado alienado do homem em suas próprias criações se tornou algo enraizado. Pode-se assumir que, suscetível a diferentes abordagens e perspectivas, a consideração de tal aspecto pode ser vista como o trampolim para várias reflexões sobre os diversos aspectos da realidade humana (LAING, 1967).

É por este motivo que os teóricos humanistas não se atêm somente à busca pela compreensão do processo pelo qual as realidades surgem e se sustentam, mas passam a vincular suas análises da realidade social ao desafio de se descrever alguma coisa que venha a ser um reflexo externo daquilo que está interiorizado na psique humana (MORGAN, 1980).

\section{PRISÕES PSÍQUICAS: AS ORGANIZAÇÕES HUMANISTAMENTE REPRESENTADAS}

Em decorrência aos fundamentos ontológicos nos quais a perspectiva humanista se estabelece e nos contornos sociológicos que reúnem as filosofias desta vertente, pode-se depreender que o âmbito organizacional pode se privilegiar muito dos ideais humanistas. As organizações, representantes micro da macroestrutura social, são locais privilegiados de aprisionamento psíquico (DRAGO, 1992). Atuando na intermediação entre a consciência humana e a realidade exterior, as organizações são exemplos de criações humanas que contribuem para a alienação do homem em relação ao seu verdadeiro Ser (BURRELL; MORGAN, 1979).

Tomando como base a análise de Marcuse (1975), as organizações têm um papel repressor significativo. O advento da civilização potencializou o aspecto alienante das 
criações do homem. Rotuladas como constructos sociais coisificados e aderindo o homem a si, as organizações reprimem e transubstanciam as necessidades originais do mesmo. Ou seja, a própria objetificação da mente humana é o que impede a sua apreciação da totalidade na forma como verdadeiramente se apresenta (BURRELL; MORGAN, 1979).

Pode-se dizer que o mundo organizativo consiste como um exemplo vivo de aprisionamento psíquico (GARRIDO, 2015). É nele onde os conceitos freudianos de 'princípio de prazer' e 'princípio da realidade' transparecem de forma fundamental (MARCUSE, 1975). É na organização que o homem convive com um entrave cognitivo posicionado entre sua própria consciência e o mundo social objetivado, que o permite considerá-la como única e verdadeira realidade dominante (BURRELL; MORGAN, 1979). Consequentemente, sua identidade se constrói por meio dela, o refúgio de seus medos e prazeres é visto nela, a sua visão de mundo é baseada nela, enfim, o homem se torna dominado por ela (GARRIDO, 2015).

É por este motivo que se pode afirmar que as organizações guardam semelhanças com as prisões. Pelo fato de a realidade organizacional ser resultado de um processo de corporalização de ideais provenientes da psique humana, ela carrega consigo toda a subjetividade da qual proveio e, ao mesmo tempo em que deixa transparecer, esconde os aspectos mais ocultos do Ser (GARRIDO, 2015). Pelo valor que os indivíduos lhes atribuem e pela forma que as enxergam, pode-se afirmar que as organizações se apropriam dos mesmos, a ponto de submetê-los ao seu domínio (FREDDO, 1994).

Neste aprisionamento, o entrave alienante que a organização, como seu próprio mundo social objetivado, sujeita a consciência do indivíduo faz com que ele lute por reproduzir uma realidade, muitas das vezes, artificialmente construída. Segundo Garrido (2015), assim, o indivíduo passa a agir e enxergar o mundo por meio de vieses regidos por aquilo que é reproduzido em sua própria psique, ou seja, seus medos, ansiedades, crenças, valores, visões de mundo, enfim, tudo aquilo que provém do inconsciente.

Morgan (2007) sumariza esse mérito de significação e domínio que as organizações exercem no indivíduo considerando-as como Prisões Psíquicas, construindo, para tanto, uma metáfora que ilustra essa reflexão acerca da interpretação humana e da realidade artificialmente construída pelo indivíduo na organização. Tal metáfora descreve um grupo de pessoas que habitam no interior de uma caverna subterrânea. Estes indivíduos estão 
posicionados de costas para a entrada da caverna, com seus pescoços e pés acorrentados e tudo que são capazes de ver é a parede da caverna (GAARDER, 1995; MORGAN, 2007).

Atrás destas pessoas ergue-se um muro alto e por trás deste passam figuras de formas humanas e, como há uma fogueira queimando atrás destas figuras, elas projetam na parede da caverna sombras bruxuleantes. Esse teatro de sombras é a única coisa que as pessoas da caverna podem ver e, como estão ali desde que nasceram, acham que as sombras que veem são a única coisa que existe. Os moradores da caverna tomam as sombras por realidade, Ihes atribuem nomes, conversam com elas e até mesmo fazem a ligação dos sons de fora com os movimentos que observam na parede (GAARDER, 1995; MORGAN, 2007).

Em um dado momento, um desses indivíduos da caverna consegue se libertar da prisão. Primeiramente ele se pergunta de onde estariam vindo as sombras projetadas na parede. Depois consegue se libertar dos grilhões que o prendem. Quando olha para trás, primeiro a luz é tão intensa que não o permite enxergar. Em seguida, a precisão dos contornos das figuras, até então vistas como sombras, ofusca sua visão. Ele, então, começa perceber que as sombras nada mais são que reflexos obscuros de uma realidade mais complexa e vê que os conhecimentos e as percepções de seus antigos companheiros são imperfeitas e distorcidas (GAARDER, 1995; MORGAN, 2007).

Se o indivíduo voltasse à caverna, não seria capaz de viver como antes, visto que para ele o mundo seria um lugar bastante diferente e teria dificuldade em aceitar o confinamento. Se tentasse compartilhar com seus colegas seu novo conhecimento, ele seria ridicularizado, já que as imagens com as quais estão acostumados possuem um significado superior do que um mundo que eles nunca viram (GAARDER, 1995; MORGAN, 2007).

Além disso, já que o indivíduo portador do novo conhecimento não seria capaz de agir com conviç̧ão em relação às sombras, seus próprios companheiros passariam a ver o mundo exterior como algo perigoso, que deveria ser evitado. Tal experiência poderia na verdade fazer com que eles se apegassem ainda mais a sua maneira habitual de encarar e interpretar a realidade (GAARDER, 1995; MORGAN, 2007).

Mesmo assim, o indivíduo liberto não consegue parar de pensar em seus antigos companheiros da caverna. Ao decidir voltar, ele tenta explicar aos outros que as sombras na parede não passam de trêmulas imitações da realidade. No entanto, as pessoas não 
concordam e continuam afirmando que aquilo que veem é tudo que existe. Por fim, acabam matando-o (GAARDER, 1995; MORGAN, 2007).

Pode-se dizer que tal metáfora enaltece o valor dos elementos subjetivistas nas análises organizacionais, retratando o significado inconsciente transmitido pela organização e a forma como é possível entender seus fenômenos como um reflexo externo das lutas que ocorrem no interior dos indivíduos que a compõem.

Diante do que foi exposto, é clara a maneira como os ideais humanistas-radicais convergem entre si e são representados nessa visão metafórica de organização exposta por Morgan (2007). Repousando em leito humanista, a Metáfora das Prisões Psíquicas revela o potencial alternativo desta dimensão paradigmática frente às hegemonias dominantes (DAHRENDORF, 1958; DAVIS, 1959). São as implicações específicas desta lógica metafórica que são operacionalizadas pelos ideais humanistas no âmbito organizacional (GUIDENS, 1976). Por si só, tal metáfora desafia de muitas maneiras as premissas ortodoxas de organização (MORGAN, 1980) e se constitui como um demonstrativo que reforça uma consideração não racional às interpretações e às análises dos fenômenos organizacionais, ainda sujeitas ao império objetivista que permanece muito bem entrincheirado (BURRELL, 2010).

Em síntese, a referenciação das pressuposições do Paradigma Humanista-Radical, bem como de sua representação simbólica através da Metáfora das Prisões Psíquicas (MORGAN, 2007), consiste em uma forma de desvendar e expandir os caminhos científicos em direções mais promissoras de um melhor entendimento dos fenômenos organizacionais (BASTOS; BORGES-ANDRADE, 2009; TENBRUNSEL et al., 2009).

\section{CONSIDERAÇÕES FINAIS}

Considerando as investigações feitas, pode-se depreender que o paradigma sociológico-organizacional Humanista-Radical se apresenta como uma alternativa frente hegemonia objetivista imperante no campo científico da Administração. Pelo fato de posicionar-se no extremo contraposto ao paradigma funcionalista (ABDOLLAHI; SHAHRIARI, 2017), o ideal humanista-radical é firmado em uma completa inversão das abordagens sobre 
a natureza da ciência e da sociedade (BURRELL; MORGAN, 1979) nas quais repousa grande parte das teorias organizacionais.

Embora ainda pouco explorado no viés organizativo de análise, pode-se considerar o paradigma humanista como uma coletânea diferenciada de preceitos, ideias e pareceres detentora de uma grande relevância ao estudo das organizações. Sendo assim, trabalhar segundo uma simbologia representativa do paradigma humanista-radical é o mesmo que se empenhar em enfatizar novos olhares para os fenômenos do mundo organizativo, visando entender os problemas organizacionais considerando o contexto no qual se desenvolvem (ABDOLLAHI; SHAHRIARI, 2017; MOZZATO; GRZYBOVSKI, 2011).

Por reconhecerem a grande contraposição dos ideais humanistas frente àqueles já institucionalizados no campo científico da administração, Burrel e Morgan (1979) afirmam que as implicações deste viés de análise ao estudo das organizações resultariam em uma teoria antiorganizacional, posicionada em fundamental oposição frente à teoria da organização contemporânea. Esta postura "antiortodoxa" se deve ao fato de que, ao empenhar-se no estudo das organizações, o ideal humanista-radical vê a filosofia funcionalista dominante como algo que mistifica o entendimento do verdadeiro significado que as organizações desempenham na sociedade e, portanto, se esforça para inverter a problemática organizacional funcionalista em todos os sentidos, baseando-se em uma tradição completamente diferente (ABDOLLAHI; SHAHRIARI, 2017; GARRIDO, 2015).

A este respeito, Mozzato e Grzybovski (2011) enfatizam que o humanismo-radical propõe uma visão de mundo mais crítica, enfatizando outra perspectiva para se perceber as organizações, ou seja, percebê-las como as mesmas se encontram inseridas e influenciam o contexto social, assim como entender o verdadeiro papel e significado que lhes é atribuído.

Os adeptos da teoria antiorganizacional alegam que, da forma como costumeiramente são vistas, as organizações assumem um status ontológico precário. Isso porque a visão contemporânea perpetua, com realce, o divórcio entre a consciência humana e a totalidade. Ou seja, é dominante a negligência em relação aos aspectos subjetivos da existência humana e no papel que ela exerce em cada ação social (GARRIDO, 2015). A filosofia humanista, por sua vez, considera o indivíduo como o centro de todas as coisas e pressupõe que, uma vez compreendido, pode-se compreender toda a vida organizacional associada a ele (GARRIDO, 2015). 
Sendo assim, o paradigma humanista-radical se posiciona em contraposto a esse status ontológico predominante e fundamenta-se na visão de que a organização tem uma existência intersubjetiva, posicionando-se como um constructo social materializado por meio do qual o indivíduo, que assim o criou, se relaciona com o mundo no qual vive (BURRELL; MORGAN, 1979).

Isso significa que esta corrente sociológica não permite idealizar a organização como algo externo à consciência individual, e sim como uma entidade socialmente criada que intervém entre a consciência do indivíduo e a forma como ele aprecia a natureza da totalidade que o cerca (GARRIDO, 2015). Grande parte das análises organizacionais é marcada pelo emudecimento dos indivíduos. Ao fundamentar-se nessa visão de organização e posicionar-se em oposição aos preceitos ontológicos predominantes, torna claro que a perspectiva humanista resgata a figura do indivíduo nas análises organizacionais e enaltece seu papel como criador da própria realidade organizacional.

Os humanistas proferem uma nova concepção de homem na sociedade, o posicionando como ator e não como sujeito ingênuo e atônito diante da realidade tal como se apresenta (MOZZATO; GRZYBOVSKI, 2011). Em contraposto à percepção positivista dos teóricos que seguem os preceitos funcionalistas, nos estudos organizacionais aderidos à concepção humanista o indivíduo é reconhecido como um ser que deixa de ser meio, ou um mero fator subordinado a outro, para ocupar um papel central (LEITÃO; LAMEIRA, 2005) e ser considerado ator principal e não sujeito das transformações (MOZZATO; GRZYBOVSKI, 2011).

Desta forma, pode-se afirmar que assumir uma postura humanista nas análises dos fenômenos organizacionais é procurar ver e interpretar as coisas tentando se livrar de pressupostos e marcos teóricos, colocando o indivíduo, e não as ideologias, no centro de todas as coisas (ESPEJO, 2008).

Neste aspecto, em justificativa a menção deste estudo à vertente metafórica do paradigma em questão, cabe ressaltar que a teoria organizacional é, por si só, metafórica e essencialmente subjetiva (MORGAN, 1980). Cada uma das escolas de pensamento dedicada a ela tem como base implicações específicas associadas a diferentes metáforas de análise organizacional (GARRIDO, 2015). Sendo assim, as pressuposições filosóficas concernentes à entidade paradigmática Humanista-Radical fundamentam e são simbolicamente 
representadas pela Metáfora das Prisões Psíquicas (MORGAN, 2007), uma lógica metafórica que garante insights importantes ao processo de construção teórica delineado pelo paradigma em questão.

Ao partir desta premissa metafórica, os humanistas simbolicamente consideram os indivíduos da organização como prisioneiros de um modo de consciência que é controlado e moldado segundo processos ideológicos profundos (MORGAN, 1980). Sendo assim, ao debruçar-se na tentativa de compreensão da forma como ele conceitua, interpreta e confere sentido aos eventos ou processos organizacionais, torna-se possível tomar sentido às decisões, comportamentos e ações que configuram resultados para si mesmo e para a própria organização.

Em suma, o paradigma Humanista-Radical apresenta-se como uma tentativa de desenvolvimento teórico alternativo para expandir os limites do campo científico da Administração e prover um insight analítico, de fundamento não racional, aos debates que permeiam a realidade das organizações. Assim sendo, este estudo contribuiu para reafirmar as bases subjetivistas das análises organizacionais, estabelecendo-as não como meras realidades de pesquisas alternativas comprimidas pelo objetivismo analítico predominante, mas como detentoras de conceitos, ideias e visões que devem ser considerados para a real compreensão do comportamento organizativo.

\section{REFERÊNCIAS}

ABDOLLAHI, B; SHAHRIARI, B. Critique of anti-organization theory based on its philosophical foundations. European Journal of Management and Marketing Studies, v.2, n. 3, 2017, p. 86-97.

BASTOS, A. V. B.; BORGES-ANDRADE, J. E. Nota técnica: cognição e ação: o ator ocupa a cena nos estudos organizacionais. In: CALDAS, M.; FACHIN, R.; FISCHER, T. Handbook de estudos organizacionais: ação e análise organizacionais. São Paulo: Atlas, 2009, p. 69-76.

BURRELL, G. Ciência normal, paradigmas, metáforas, discursos e genealogia da análise. In: CALDAS, M.; FACHIN, R.; FISCHER, T. Handbook de estudos organizacionais: modelos de análise e novas questões em estudos organizacionais. São Paulo: Atlas, 2010, p. 437-460.

BURRELLL, G.; MORGAN, G. Sociological paradigms and organizational analysis. London: Heinemann Educational Books, 1979. 
CALDAS, M. P.; FACHIN, R. Paradigma funcionalista: desenvolvimento de teorias e institucionalismo nos anos 1980 e 1990. Revista de Administração de Empresas, São Paulo, v. 45, n. 2,2005 , p. 46-51.

CLEGG, S. R.; HARDY, C. Conclusão: representação. In: CALDAS, M.; FACHIN, R.; FISCHER, T. Handbook de estudos organizacionais: reflexões e novas direções. São Paulo: Atlas, 2009, p. 295-343.

DAHRENDORF, R. Out of utopia: toward a re-orientation of sociological theory. American Journal of Sociology, v.LXIV, p.115-127, 1958.

DAVIS, K. The myth of functionalism as a special method in sociology and anthropology. American Sociological Review, v. 24, 1959, p.757-72.

DRAGO, P.A. Teoria crítica e teoria das organizações. Revista de Administração de Empresas, São Paulo, v. 32, n. 2, 1992, p. 58-64.

ESPEJO, R. Humanismo radical, decrecimiento y energía: una lectura de las ideas de Iván Illich. Revista de la Universidad Bolivariana, Santiago, v. 7, n. 21, 2008, p. 63-79.

FEYERABEND, P. Contra o método. Rio de Janeiro: Francisco Alves, 1977.

FINEMAN, S. A emoção e o processo de organizar. In: CALDAS, M.; FACHIN, R.; FISCHER, T. Handbook de estudos organizacionais: reflexões e novas direções. São Paulo: Atlas, 2009, p.157-189.

FITCHE, J.G. The science of knowledge. London: Trübner \& Co., 1889.

FREDDO, A.C. O discurso da alienação nas organizações. Revista de Administração Pública, Rio de Janeiro, v. 28, n. 1, 1994, p. 24-33.

GAARDER, J. 0 mundo de Sofia: romance da história da filosofia. São Paulo: Companhia das Letras, 1995.

GARRIDO, G. Uma abordagem subjetivista da resistência dos executivos à mudança: análise de duas corporações americanas. Dissertação de Mestrado desenvolvida no Programa de Pós-Graduação em Engenharia de Produção - Universidade Federal de São Carlos - UFSCar Campus Sorocaba, 2015, 144p.

GIDDENS, A. New Rules of Sociological Method. London: Hutchinson, 1976.

GOULDNER, A. The Coming Crisis of Western Sociology. London: Heinemann, 1970.

HARRIS, W.T. Preface. In: FITCHE, J.G. The science of knowledge. London: Trübner \& Co., 1889 , p. 3-23. 
HOLMWOOD, J. Functionalism and its critics. In modern social theory: An introduction, Oxford: Oxford University Press, v.2, 2005, p. 87-109.

HOMANS, G.C. Bringing men back. American Sociological Review, v. 29, 1964, p. 809-818

LAING, R.D. The politics of experience and the bird of paradise. England: Penguin Books, 1967.

LEITÃO, S.P.; LAMEIRA, V.J. Humanismo e mudança organizacional. Revista de Administração Pública, Rio de Janeiro, v. 39, n. 3, 2005, p.731-751.

LIMA, L. A. de. A representação das múltiplas dimensões paradigmáticas no estudo da administração: um ensaio sobre os limites contidos nas defesas paradigmáticas excludentes. Revista de Administração Contemporânea, Curitiba, v. 15, n. 2, 2011, p. 198-208.

MARCUSE, H. Eros e civilização: uma interpretação filosófica do pensamento de Freud. 6. ed. Rio de Janeiro: Zahar, 1975.

MEDEIROS, A.L.; TEIXEIRA, M.L.M. Gerenciando pessoas. Mas com que paradigma? Revista Brasileira de Estudos Organizacionais, v. 1. n. 2, 2014, p. 212-230.

MELO, D. R. A. de. A questão do método e a pluralidade metodológica em estudos organizacionais. In: SIMPÓSIO DE EXCELÊNCIA EM GESTÃO E TECNOLOGIA, 5., 2008, Resende. Anais SIMPOI Resende: UFAM, 2008. Disponível em: <http://bit.ly/1wba8T8>. Acesso em: 20 fev. 2018.

MERTON, R.K. Manifest and latent functions. Social Theory and Social Structure. Free Press: New York, 1968.

MILLS, C.W. The Sociological Imagination. Oxford: Oxford University Press, 1959.

MORGAN, G. Imagens da organização. 2. ed. São Paulo: Atlas, 2007.

MORGAN, G. Paradigms, metaphors, and puzzle solving in organization theory. Administrative Science Quarterly, Ithaca, v. 25, n. 4, 1980, p. 605-622.

MORGAN, G.; SMIRCICH, L. The case for qualitative research. Academy of Management Review, Ada, v. 5, n. 4, 1980, p. 491-500.

MOZZATO, A.R.; GRZYBOVSKI, D. Desenvolvimento paradigmático da teoria das organizações: uma abordagem crítica e a concepção de indivíduo na perspectiva emancipatória. In: COLÓQUIO DE ESPISTEMOLOGIA E SOCIOLOGIA DA CIÊNCIA DA ADMINISTRAÇÃO, 1., 2011, Florianópolis. Anais. Florianópolis: UFSC, 2011. Disponível em: <http://bit.ly/1p59rZT>. Acesso em: 20 fev. 2018.

PARSONS, T. The Structure of Social Action. New York: Free Press, 1937. 
PAULA, A.P.P. Para além dos paradigmas nos estudos organizacionais: O Círculo das Matrizes Epistêmicas. Cadernos Ebape.Br, v.14, n.1, Rio de Janeiro, 2016, p.24-46.

PECl, A. Estrutura e ação nas organizações: algumas perspectivas sociológicas. Revista de Administração de Empresas, São Paulo, v. 43, n. 1, 2003, p. 24-35.

PRATES, A. A. P.; RODRIGUES, S. B. Nota técnica: representações - a importância do sujeito na teoria organizacional. In: CALDAS, M.; FACHIN, R.; FISCHER, T. Handbook de estudos organizacionais: reflexões e novas direções. São Paulo: Atlas, 2009. p. 344-352.

REED, M. Teorização organizacional: um campo historicamente contestado. In: CALDAS, M.; FACHIN, R.; FISCHER, T. Handbook de estudos organizacionais: modelos de análise e novas questões em estudos organizacionais. São Paulo: Atlas, 2010, p. 61-97.

SANTOS, E.L. The scientific field of administration: an analysis from the circle of theoretical matrices. Cadernos EBAPE.BR, Rio de Janeiro, v. 15, n.2, 2017, p. 209-228.

SARTRE, J. Being and nothingness: the complete text. New York: Washington Square Press, 1966.

SILVA, J. R. G. da; VERGARA, S. C. Sentimentos, subjetividade e supostas resistências à mudança organizacional. Revista de Administração de Empresas, São Paulo, v. 43, n. 3, 2003, p. 10-21.

TENBRUNSEL, A. E. et al. Cognições em organizações. In: CALDAS, M.; FACHIN, R.; FISCHER, T. Handbook de estudos organizacionais: ação e análise organizacionais. São Paulo: Atlas, 2009 , p. 33-68.

VERGARA, S. C. Nota técnica: ciência normal, paradigmas, metáforas, discursos e genealogias da análise. In: CALDAS, M.; FACHIN, R.; FISCHER, T. Handbook de estudos organizacionais: modelos de análise e novas questões em estudos organizacionais. São Paulo: Atlas, 2010, p. 461-463.

VERGARA, S.C.; CALDAS, M.P. Paradigma interpretacionista: a busca da superação do objetivismo funcionalista nos anos 1980 e 1990. Revista de Administração de Empresas, São Paulo, v. 45. n. 4, 2005, p. 66-72.

WILLMOTT, H. Breaking the Paradigm Mentality. Organization Studies, v.14, 1993, p. 681719.

Recebido em: 28.11.2017

Aprovado em: 29.05.2018 